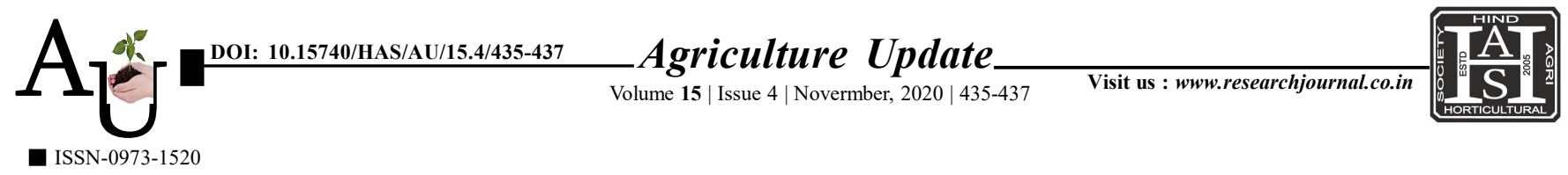

A ReVIEW :

\title{
Artificial intelligence - The promise for an agricultural revolution in new era
}

\author{
Reshma J. Murugan, B. N. Bindhya and G. S. Sreedaya
}

Article Chronicle :

Received :

15.02.2020;

Accepted :

$22 . .10 .2020$

KeY Words :

Artificial intelligence, Agriculture, Remote sensing, Robotics, Crop monitoring, Predictive analysis
SUMMARY : Agriculture is slowly becoming digital. The adoption of Artificial Intelligence (AI) and Machine Learning (ML) both in terms of agricultural products and in-field farming techniques are increasing. Artificial Intelligence in agriculture is emerging in three major areas, namely agricultural robotics, soil and crop monitoring and predictive analytics. The use of sensors and soil sampling techniques are increasing day by day which helps in gathering of data. In turn, this data is stored in farm management system which is better processed and analysed. Thus, the data available along with other related data paves a way to successfully deploy AI in agriculture. AI in agriculture is emergingin cognitive computing and it has all the scope to become the most disruptive technology in agriculture services as it is able to understand, learn and respond to different situations (based on learning) to increase efficiency. The areas where the use of cognitive solutions can benefit agriculture are growth driven by IOT, image-based insight generation, identification of optimal mix for agronomic products, health monitoring of crops and automation techniques in irrigation and enabling farmers. In addition, the drone based solutions have significant impact in terms of productivity gains, coping with adverse weather conditions, yield management and precision farming. The emergence of new age technologies like Artificial Intelligence (AI), Cloud Machine Learning, Satellite Imagery and advanced analytics are creating an ecosystem for smart farming. Fusion of all this technology is enabling farmers achieve higher average yield and better price control.

How to cite this article : Murugan, Reshma J., Bindhya, B.N. and Seedaya, G.S. (2020). Artificial intelligence - The promise for an agricultural revolution in new era. Agric. Update, 15(4): 435-437; DOI : 10.15740/HAS/AU/ 15.4/435-337. Copyright@ 2020: Hind Agri-Horticultural Society.
Author for correspondence :

Reshma J. Murugan College of Agriculture, Kerala Agricultural University, Vellayani

(Kerala) India

Email:

reshma.su16@gmail.com

See end of the article for authors' affiliations 